suspect feed. ${ }^{11}$ If, therefore, eating infected beef can cause Creutzfeldt-Jakob disease the development of the disease is likely to be greatly delayed.

Creutzfeldt-Jakob disease is rare: its incidence in England and Wales is 0.49 per million. ${ }^{12}$ Although it can be transmitted in the laboratory to several animal species - usually only by intracerebral injection of brain extracts and exceptionally from person to person by iatrogenic accident ${ }^{7}-$ it is by no means established that the disease is naturally infectious. There have been occasional reports of social contact between patients with overt disease ${ }^{13}$ and three instances of CreutzfeldtJakob disease in neuropathology technicians. ${ }^{1+16} \mathrm{~A}$ small casecontrol study showed a remarkable number of "significant" medical, dietary, and other environmental risk factors, ${ }^{17}{ }^{18}$ but none that were examined could be confirmed in a much larger investigation in Britain. ${ }^{12} \mathrm{~A}$ significant excess of CreutzfeldtJakob disease or other dementing illness is found in close relatives of patients with the disease, ${ }^{12}$ but almost all cases are sporadic. No source of infection or route of entry has been confirmed, and no environmental factor has been identified that might convert a normal protein into a destructive prion. ${ }^{19}$

Understandably, great attention has been paid to the possibility that people might acquire Creutzfeldt-Jakob disease from sheep affected by scrapie, particularly from eating brains, and a few suggestive anecdotes. have been reported..$^{20}$ Anyone in Britain who eats meat will have eaten mutton, and a case-control study could not be expected to detect any excess consumption in those with CreutzfeldtJakob disease. Studies of other contacts with sheep or their products have found no differences from controls. ${ }^{12}$ The incidence of Creutzfeldt-Jakob disease in countries where scrapie has never been found ${ }^{212}$ is similar to that in Britain and France, ${ }^{1+}$ where scrapie has been present for many years. Creutzfeldt-Jakob disease may occur in life long vegetarians, ${ }^{23}$ though it must be admitted that until recently cattle were also thought to be in this category. "Mad cow disease" has naturally caused alarm that might have been mitigated by emphasising that we have long been exposed to the equally mad sheep disease without any demonstrable harm.

What then should be done? Research with "slow viruses" cannot possibly yield rapid results. Further attempts will be made to transmit spongiform encephalopathy from beef and milk to laboratory animals, preferably primates, both by intracerebral injection and by oral administration, but such studies will not answer the question of whether any infection present in beef can cross the species barrier to humans.
An answer could be found only by extremely prolonged monitoring of the incidence of Creutzfeldt-Jakob disease. A baseline exists for the years 1980-4 in England and Wales, ${ }^{12}$ but the task is formidable as every suspected case must be seen by a neurologist who is familiar with the disease. A high necropsy rate is essential and would be difficult to sustain. Such monitoring would identify any large increase in incidence but could not detect or exclude occasional instances of transmission from any environmental source. Repeated claims that British beef is entirely safe to eat are very probably true and largely supported by the opinion of the Southwood committee $^{3}$; but such claims are scarcely scientific when the question has not been tested and is, perhaps, untestable.

Retired Professor of Clinical Neurology,

W B MATTHEWS Oxford OX4 4YN

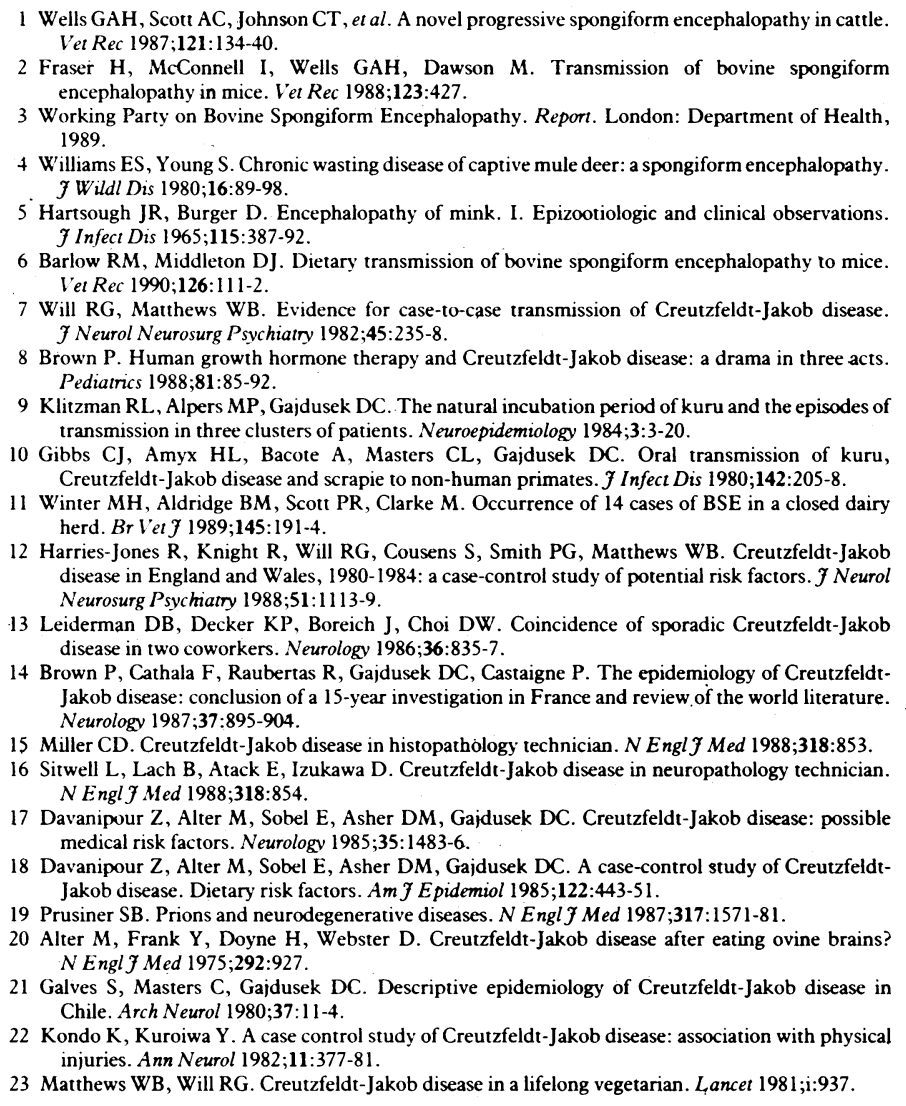

12 Harries-Jones R, Knight R, Will RG, Cousens S, Smith PG, Matthews WB. Creutzfeldt-Jakob disease in England and Wales, 1980-1984: a case-control study of potential risk factors. $\mathcal{F}$ Neurol Neurosurg Psychiatry 1988;51:1113-9.

13 Leiderman DB, Decker KP, Boreich J, Choi DW. Coincidence of sporadic Creutzfeldt-Jakob disease in two coworkers. Neurology 1986;36:835-7.

14 Brown P, Cathala F, Raubertas R, Gajdusek DC, Castaigne P. The epidemiology of CreutzfeldtJakob disease: conclusion of a 15-year investigation in France and review of the world literature. Neurology 1987;37:895-904.

15 Miller CD. Creutzfeldr-Jakob disease in histopathology technician. N Engl f Med 1988;318:853. 16 Sitwell L, Lach B, Atack E, Izukawa D. Creutzfeldt-Jakob disease in neuropathology technician. N Engl F Med 1988;318:854.

17 Davanipour Z, Alter M, Sobel E, Asher DM, Gajdusek DC. Creutzfeldt-Jakob disease: possible medical risk factors. Neurologv 1985;35:1483-6.

18 Davanipour Z, Alter M, Sobel E, Asher DM, Gajdusek DC. A case-control study of CreutzfeldtJakob disease. Dietary risk factors. Am $\mathcal{F}$ Epidemiol 1985;122:443-51.

9 Prusiner SB. Prions and neurodegenerative diseases. $N$ Engl f Med 1987;317:1571-81

20 Alter M, Frank Y, Doyne H, Webster D. Creutzfeldt-Jakob disease after eating ovine brains? Alter M, Frank Y, Doyne H,
N Engl f Med 1975;292:927.

21 Galves S, Masters C, Gajdusek DC. Descriptive epidemiology of Creutzfeldt-Jakob disease in Chile. Arch Neurol 1980;37:11-4

22 Kondo K, Kuroiwa Y. A case control study of Creutzfeldt-Jakob disease: association with physical injuries. Ann Neurol 1982;11:377-81.

23 Matthews WB, Will RG. Creutzfeldt-Jakob disease in a lifelong vegetarian. Lancet 1981;i:937.

\title{
The new dermatology
}

\section{Improved understanding should yield better treatment}

The recent explosion of knowledge in biomedical science as it relates to the skin offers the possibility of dramatic improvement in our understanding of the aetiology and pathophysiology of important skin diseases - and a possible translation of that understanding into improved diagnosis and treatment.

In non-melanoma skin cancer molecular biological methods are clarifying the part played by specific types of human papillomavirus - 16 and 18 -in squamous carcinoma. Type 16 transforms keratinocytes, but its oncogenicity has been controversial-largely because of differences in the sensitivity of the detection techniques used. ${ }^{12}$ The application of the polymerase chain reaction technique should, however, establish to what extent DNA from human papillomavirus 16 and its subtypes becomes integrated into the cell genome in normal healthy epidermis and in invasive lesions.

More efforts are being directed towards prevention of skin cancer. Sunscreens may be of limited value because they fail to block the immunosuppressive effect of ultraviolet radiation. ${ }^{3}$ It may prove possible to reverse the mutagenic dimerisation of DNA induced by ultraviolet radiation by using a DNA repair endonuclease derived from viral sources. The first recipients of this treatment might be patients with xeroderma pigmentosum (who have a hereditary deficiency of 
DNA repairing enzymes). The clinical similarities of the cutaneous $T$ cell lymphoma mycosis fungoides to the recently recognised human $T$ cell leukaemia lymphoma, known to be due to infection with the human $T$ cell lymphotropic virus-I (HTLV-I) has prompted discussion of the possible part played by transforming retroviruses in mycosis fungoides. Further evidence for such a connection is the recent description of a new human retrovirus, HTLV-V, in human T cell lymphoma.

Until now, attempts to establish a rational basis for development of new topical anti-inflammatory drugs as alternatives to corticosteroids have been unsuccessful. This has been due in part to concentration on specific mediators; the inflammatory dermatoses seem clearly to result from the orchestrated action of multiple mediators. ${ }^{6} \mathrm{New}$ information on the earliest cellular and molecular events in the development of inflammation of the skin has drawn attention to glycoprotein leucocyte adhesion receptor molecules. These are collectively termed the leucocyte integrins and are exemplified by lymphocyte function associated antigen-1 (LFA-1), the receptor for CD4 $\mathrm{T}$ lymphocytes; their corresponding endothelial ligands are exemplified by intracellular adhesion molecule-1 (ICAM-1), which is specific to LFA-1. ${ }^{7}$ Of special interest is the observation by Nickoloff that expression of ICAM-1 is increased on both endothelial cells and keratinocytes in dermatoses that histologically manifest epidermotropism, including psoriasis, mycosis fungoides, and lichen planus. ${ }^{8}$ This response, which explains the epidermal "trapping" of the Thelper-inducer lymphocytes in these disorders, can be reproduced by interferon gamma. ${ }^{8}$ The development of new cloning methods and the possibility of modifying these adhesion molecules so as to clarify. their activation and distribution should offer an exciting new approach to developing anti-inflammatory compounds. It will have the added advantage of acting "upstream" in the cascade of molecular events which lead to inflammation, so that any action is likely to be common to a wide range of dermatoses.

Another exciting prospect is some form of replacement treatment in genodermatoses in which structural proteins or enzymes are missing. Somatic gene therapy or the development of engineered proteins with a prolonged half life and reduced immunogenicity, especially if targeted towards particular cell types, ${ }^{9}$ remains a very long term goal. More immediately the impending availability of DNA probes should enable early ( 10 weeks' gestation) prenatal diagnosis in chorionic villus samples of genodermatoses in which the gene defect is known or linkage analysis in instances where the defect is unknown. We are likely to see the first reports of DNA probe applications in this field of dermatology over the next few years. ${ }^{10}$

Itch (and pain) are predominant symptoms of skin disease, yet steps to define their pathophysiology have been at best faltering. Both sensations seem to be transmitted via unspecialised dermoepidermal nerve endings through unmyelinated polymodal $\mathrm{C}$ fibres. The possibility that these sensory nerves might play a part in inflammation was initially suggested by the immunocytochemical finding in cutaneous sensory nerve endings of neuropeptides including substance $P$, calcitonin gene related peptide, and vasoactive intestinal peptide. Depletion of substance $P$ by local application of capsaicin caused inhibition of the axon reflex flare, neurogenic inflammation, pain, and itch in treated skin, ${ }^{11}$ and it is becoming possible to develop satisfactory immunoassay and mass spectrometric techniques to identify and measure these unstable peptides in biological matrices. ${ }^{12}$ Opioid neuropeptides are also now recognised as important in regulating sensory nerve traffic in the central nervous. system.

Patients with intractable itching can be separated into responders and non-responders to placebo depending on their response to the opioid antagonist naloxone, ${ }^{13}$ and specific receptors for the endorphins have now been recognised in the central nervous system. ${ }^{1+}$ These developments should eventually clear up the continuing controversy on the relative importance of peripheral and central mechanisms mediating the intense pruritus of atopic eczema. ${ }^{\prime}$

Apart from being an encouraging occurrence in itself the advent of new drugs for treating intractable skin diseases may also shed new light on the pathogenesis of the disease in question, especially if the drug has a recognised and reasonably specific mode of action. For example, the effects of cyclosporin A at the molecular level are complex, but the drug does have a selective immunosuppressive action on signals derived from $T$ cells to accessory cells, preventing augmented synthesis of interleukin 1 and interleukin 2 and thus preventing the proliferation of CD4 $\mathrm{T}$ helper-inducer cells. Recent reports have described the dramatic effects of cyclosporin $A$ in treating intractable psoriasis. ${ }^{16}$ When these are considered in relation to recent immunopharmacological studies in psoriasis that highlight the pathogenic contributions of T lymphocyte subsets and immunoregulatory cytokines ${ }^{718}$ the overall picture now suggests that cellular immune mechanisms may play a key part in this disorder.

These and many other related issues in dermatology will be discussed in a forthcoming international symposium, "Clinical Dermatology in the Year 2000" to be held in the Barbican Centre, London, on 22-25 May 1990. The meeting is designed to show dermatologists how major advances in the biomedical sciences are likely to affect their practices by the end of the millennium. The symposium should also highlight the increasing impact that current dermatological research is having on understanding of the pathophysiology of inflammation in non-cutaneous organs and tissues. It is organised by the Institute of Dermatology, United Medical and Dental Schools of Guy's and St Thomas's Hospitals.

MALCOLM W GREAVES

Professor in Dermatology,

St John's Hospital for Diseases of the Skin,

London WC2H 7BJ

1 Young LS, Bevan IS, Johnson MA, et al. The polymerase chain reaction: a new epidemiological tool for investigating cervical human papillomavirus infection. Br Med $\mathcal{F}$ 1989;298:14-8.

2 Tidy JA, Parry GCN, Ward P, et al. High rate human papilloma virus type 16 infection in cytologically normal cervices. Lancet 1989;i:434.

3 Fisher MS, Menter JM, Willis I. Ultraviolet radiation-induced suppression of contact hyposensitivity in relation to padimate $\mathrm{O}$ and oxybenzone. $\mathcal{F}$ Invest Dermatol 1989;92:337-41.

Ceccoli J, Rosales N, Tsimis J, Yarosh DB. Encapsulation of the UV-DNA repair enzyme T4 endonuclease $V$ in liposomes and delivery to human cells. F Invest Dermatol 1989;93:190-4

Manzari V, Gismondi A, Barillari A, et al. A new human retrovirus isolated in a tac-negative $\mathrm{T}$ cell lymphoma-leukaemia. Science 1987;238:1581-3.

lymphoma-leukaemia. Science 1987;238:1581-3.
Greaves MW. Inflammation and mediators. Br f Dermatol 1988;119:419-26.

6 Greaves MW. Inflammation and mediators. Brf Dermatol 1988;119:419-26. integrins. LFA-1, MAC-1 and P150,95. Adv Immunol 1989;46:149-82.

integrins. LFA-1, MAC-1 and P150,95. Adv Immunol 1989;46:149-82.
Nickoloff BJ. Role of interferon gamma in cutaneous trafficking in lymphocytes with emphasis on ickoloff BJ. Role of interferon gamma in cutaneous trafficking in lymphoct
cellular and molecular adhesion events. Arch Dermatol 1988;124: 1835-43.

9 Hershfield MS, Buckley RH, Greenberg ML, et al. Treatment of adenosine deaminase deficiency with polyethylene glycol-modified adenosine deaminase. $N$ Engl f Med 1987;316:589-96.

10 Eady RAJ. Prenatal diagnosis. In: Orfanos CE, Stadler R, Gollnick H, eds. Proceedings of the seventeenth world congress of dermatology. Berlin: Springer Verlag, 1988:127-31.

11 Carpenter SE, Lynn B. Vascular and sensory responses of human skin to mild injury after topical treatment with capsaicin. Brf Pharmacol 1981;73:755-61.

12 Mallet AI, Rose K, Priddle JD. Development of a GCMS assay for the two eosinophil chemotactic factors of anaphylaxis. Biomedical Mass Spectrometry 1983;10:120-5.

13 Summerfield JA. Naloxone modulates the perception of itch in man. $\mathrm{Br} f$ Clin Pharmacol 1980;10:180-2.

14 Bernstein JJ. Butorphanol-induced pruritis antagonized by naloxone. Am Acad Dermatol 1989;5:277-31.

15 Krause L, Shuster S. Mechanism of action of antipruritic drugs. Br Med f 1983;287:1199-200.

16 Ellis CN, Gorsulowsky DC, Hamilton TA, et al. Cyclosporin improves psoriasis in a double blind study. FAMA 1986;256:3110-6.

7 Barker BS, Swain AF, Fry L, Valdimarsson H. Epidermal T lympohocytes and HLA DR expression in psoriasis. Br $\mathcal{A}$ Dermatol 1984;110:555-64.

18 Camp RDR, Fincham NJ, Cunningham FM. Psoriatic skin lesions contain biologically active amounts of an interleukin-1-like compound. F Immunol 1986;137:3469-74 